\title{
DIVISION OF THE UTERINE VEIN AND THE FUNCTION OF THE ADJACENT OVARY IN THE EWE
}

\author{
D. T. BAIRD AND R. B. LAND \\ Department of Obstetrics and Gynaecology, University of Edinburgh, and \\ Animal Breeding Research Organization, Edinburgh EH9 372
}

(Received 12th April 1972)

\begin{abstract}
Summary. The influence of vascular connections between uterine horn and adjacent ovary on the function of the CL was investigated in twenty-four Welsh Mountain ewes. Normal luteal regression occurred in ten out of ten ewes in which all connections between the uterus and ovarian pedicle were severed except the middle uterine vein. The CL was maintained in four out of ten ewes in which the middle uterine vein alone was ligated and divided. In those ewes which returned to heat, a tubal arcade of veins anastomosing between the uterine and ovarian veins was noted. Division of these anastomotic veins in addition to the middle uterine vein inhibited luteal regression in six out of seven ewes. These results suggest that integrity of the venous connections between the uterus and ovary is essential for normal luteal regression.
\end{abstract}

\section{INTRODUCTION}

The fact that hysterectomy in the ewe results in maintenance of the CL (Wiltbank \& Casida, 1956) suggests that luteal regression in this species, as in the guinea-pig, cow and pig (Anderson, Bland \& Melampy, 1969), is influenced by the uterus. The local nature of this phenomenon was demonstrated in a series of experiments in which persistence of the CL was shown to depend on the quantity of uterine horn remaining attached to the adjacent ovary (Moor \& Rowson, 1966; Moor, 1968).

The CL fails to regress normally when the uterus and ovary are separated either by surgical division of the tissues joining these structures in situ (Inskeep \& Butcher, 1966) or by autotransplantation of ovary (Goding, McCracken \& Baird, 1967) or uterus (Goding, Harrison, Heap \& Linzell, 1967) to the neck. It has been suggested that the uterus induces luteal regression by releasing a locally effective 'luteolysin' which reaches the CL on the adjacent ovary (Short, 1967). However, the mechanism of transfer of luteolysin to the ovary is at present unknown (McCracken, Baird \& Goding, 1971).

The potential importance of the integrity of the vascular connections between the uterus and ovary for normal luteal regression is indicated by the fact that ligation of both uterine vein and artery resulted in prolonged cycles in one out of three ewes, whereas division of the uterine artery alone was without effect (Kiracofe, Menzies, Gier \& Spies, 1966). In the present study, the importance 
of the venous drainage from the uterus and ovary in luteal regression was investigated by selective ligation of the uterine veins.

\section{MATERIALS AND METHODS}

Twenty-four Welsh Mountain ewes were allocated to this experiment at the Dryden Field Laboratory, Roslin, Midlothian. Their oestrous cycles were synchronized by the use of progestagen sponges (Searle), so that the second oestrus after sponge withdrawal took place around 20th November 1971. Surgical intervention was arranged on the 6th, 7th or 8th day after the onset of the second oestrus so that two groups of ten ewes were formed at random.

In Group 1, all connections were divided between the ovarian pedicle of the ovary containing a $\mathrm{CL}$ and the adjacent uterine horn, with the exception of the middle uterine vein itself which was left intact. The division included and extended from the Fallopian tube to a point 2 to $3 \mathrm{~cm}$ beyond the junction of the uterine and ovarian veins. The uterine vein was dissected free of connective tissue for 5 to $10 \mathrm{~mm}$ close to the junction with the ovarian vein. All the CL were marked with a silk tie $(5 / 0)$.

The treatment of Group 2 was the reciprocal to that of the first, the middle uterine vein alone being ligated and divided close to the point of entry to the ovarian vein, the remaining connections between the uterus and the ovary being left intact. Again, the division was completed on a side with at least one $\mathrm{CL}$, and all CL were marked with a silk tie.

All ewes in which ligations had been performed were teased with a vasectomized ram from 1 day after surgery and all heats were recorded. The ewes were re-examined at laparotomy 17 to 20 days after ligation (23 to 26 days after the oestrus before the first operation) and the presence of any CL was noted.

Peripheral blood samples were taken from all ewes before surgery at both the time of ligation and at the time of re-examination. A sample was also collected on the 17th day after the oestrus before the first operation from all ewes which had not yet returned to oestrus. The progesterone concentration in the peripheral plasma was measured in a competitive protein-binding assay (Collett, Land \& Baird, 1973). Surgery was performed under Nembutal-induced halothane anaesthesia.

\section{RESULTS}

In Group 1, all ten ewes with unligated uterine veins returned to oestrus 16 to 19 days after the preligation oestrus. In all cases, the marked CL were noted to have regressed and new ones were observed. In Group 2, four of the ten ewes in which the uterine vein alone was ligated failed to show oestrus by the time of the re-examination when the original CL were found to have persisted. Each of the six ewes which returned to oestrus (dioestrous interval, 16 to 20 days) was observed to have at least one new CL at the second operation, the original marked CL having regressed.

In addition to the presence of CL, the vascular connections between the ovarian pedicle and its adjacent uterine horn were also inspected at the time of re-examination. In no case had the uterine veins recanalized. However, the 
presence of an arcade of vessels was noted in the mesovarium passing close to the Fallopian tube and, in some cases, ultimately joining the uterine vein to the ovarian vein (Text-fig. 1 and Plate 1). Of the six ewes which returned to oestrus following the division of the uterine vein, five were observed to have such an arcade and no record was taken of the sixth.

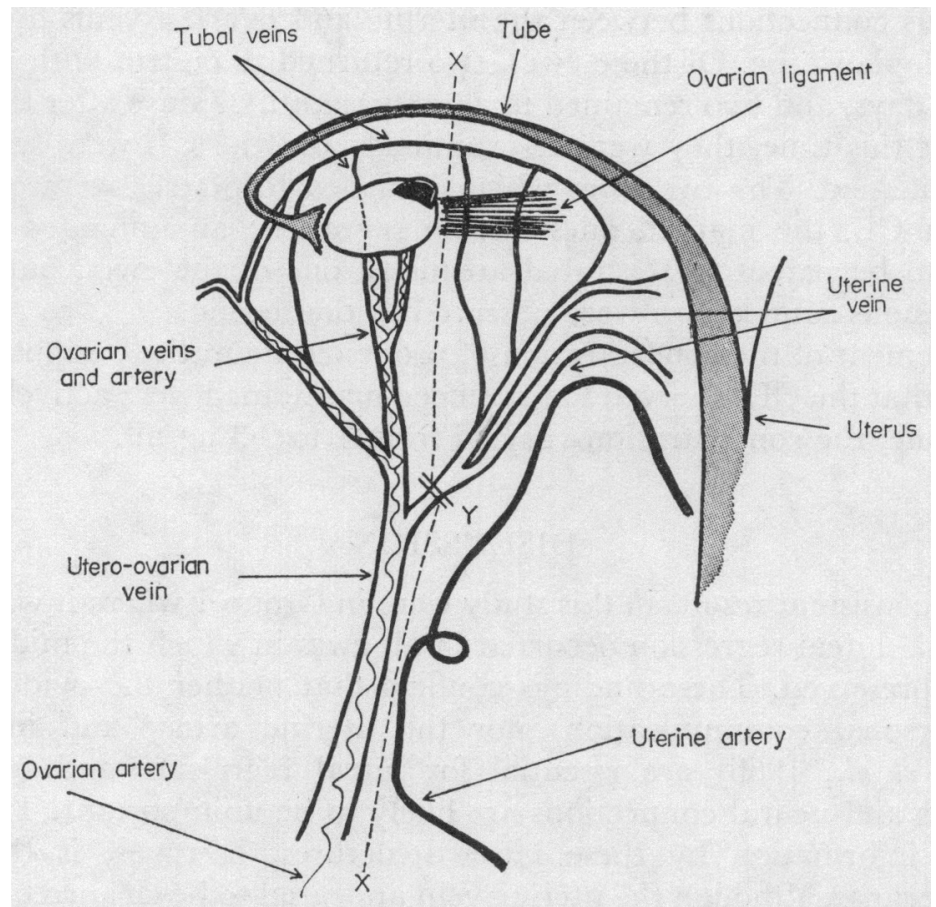

TEXT-FIG. 1. Diagrammatic representation of the vascular supply to the uterus, ovary and Fallopian tube in the ewe. In Group 1, the structures along the line $\mathrm{X}(---)$ were divided leaving the uterine vein intact. In Group 2, the uterine vein was divided and ligated at $\mathrm{Y}$.

Following the observation of this arcade of anastomosing veins, an attempt was made to investigate their rôle in the luteolytic process. Two additional groups of ewes were, therefore, prepared at the time of the second operation.

(a) In two ewes from Group 1, all connections between uterus and ovary were severed by dividing the uterine vein.

(b) In seven ewes, the middle uterine and tubal arcade of veins alone were divided, leaving the other structures intact.

In each case, the new CL were again marked with a silk tie. All ewes were teased for at least 21 days after supplementary surgery. In one ewe which returned to oestrus with a dioestrous interval of 20 days, the GL were observed to have regressed and a new one had formed. The remaining eight ewes did not return to oestrus and the recovery of the genital tracts from seven of them showed that the marked CL had been maintained. Supplementary ligation of the venous connections between the ovarian pedicle and the uterus led to the 
maintenance of the CL in six out of seven ewes, and the severance of all connections to maintenance in both of two ewes.

Following this indication of the effects of the ligation of tubal and uterine veins, this operation was performed de novo on the four remaining intact ewes on Days 11 or 12 of the oestrous cycle. The uterine vein was again ligated and divided close to the anastomosis with the ovarian vein, and all other recognizable venous connections between the uterine and ovarian veins divided close to the Fallopian tube. Of these ewes, two returned to oestrus with intervals of 18 and 19 days, and two remained in anoestrus until 27 days after the previous oestrus. At this time, they were re-examined, and the CL were seen to have been maintained. The two ewes which returned to oestrus were observed to have fresh CL, the marked ones having regressed; an unligated vessel was observed to be patent in the tubal arcade of one of the ewes, but no uteroovarian venous connections were observed in the second.

Measurement of the concentration of progesterone in the peripheral plasma indicated that the CL observed to have been maintained were actively secreting progesterone, the concentration varying from 1 to $3.3 \mathrm{ng} / \mathrm{ml}$.

\section{DISCUSSION}

The most consistent results in this study were in Group 1 where it was observed that normal luteal regression occurred in all ewes in which the middle uterine vein was preserved. These findings confirm that neither the oviduct (R. M. Moor, personal communication) nor the uterine artery and its branches (Kiracofe et al., 1966) are essential for luteal regression and suggest that lymphatics and neural connections are likely to be unimportant. Transport of luteolytic information by these latter structures, however, is theoretically possible because, although the uterine vein appeared to be cleaned of surrounding structures to the naked eye, this was not verified by microscopic examination.

The less consistent findings in Group 2, in which the uterine vein alone was ligated and divided, can be explained by the presence of a collateral venous drainage system which was not suspected until the second operation. A tubal venous arcade anastomosing with both the uterine and ovarian veins was observed in five out of six ewes in which the CL regressed (no observation in one) whereas it was absent in two of the four ewes (no observation was made of the other two ewes) which failed to return to oestrus. That these collateral venous channels may provide an alternative pathway for transport of luteolytic substance was suggested by the finding that in six of the seven ewes where they were subsequently ligated, the CL were maintained. When ligation of the uterine vein and the tubal arcade was performed as a primary procedure, only half had retained CL. These vessels became much more prominent when the middle uterine vein had been ligated for some time, which may explain the failure to ligate and divide all anastomotic vessels in these cases.

These results suggest that, as in the guinea-pig (Oxenreider \& Day, 1967; Bland \& Donovan, 1969; Fischer, 1971) and the rat (Butcher, Barley \& Inskeep, 1969), the vascular connections between uterus and ovary are essential for 


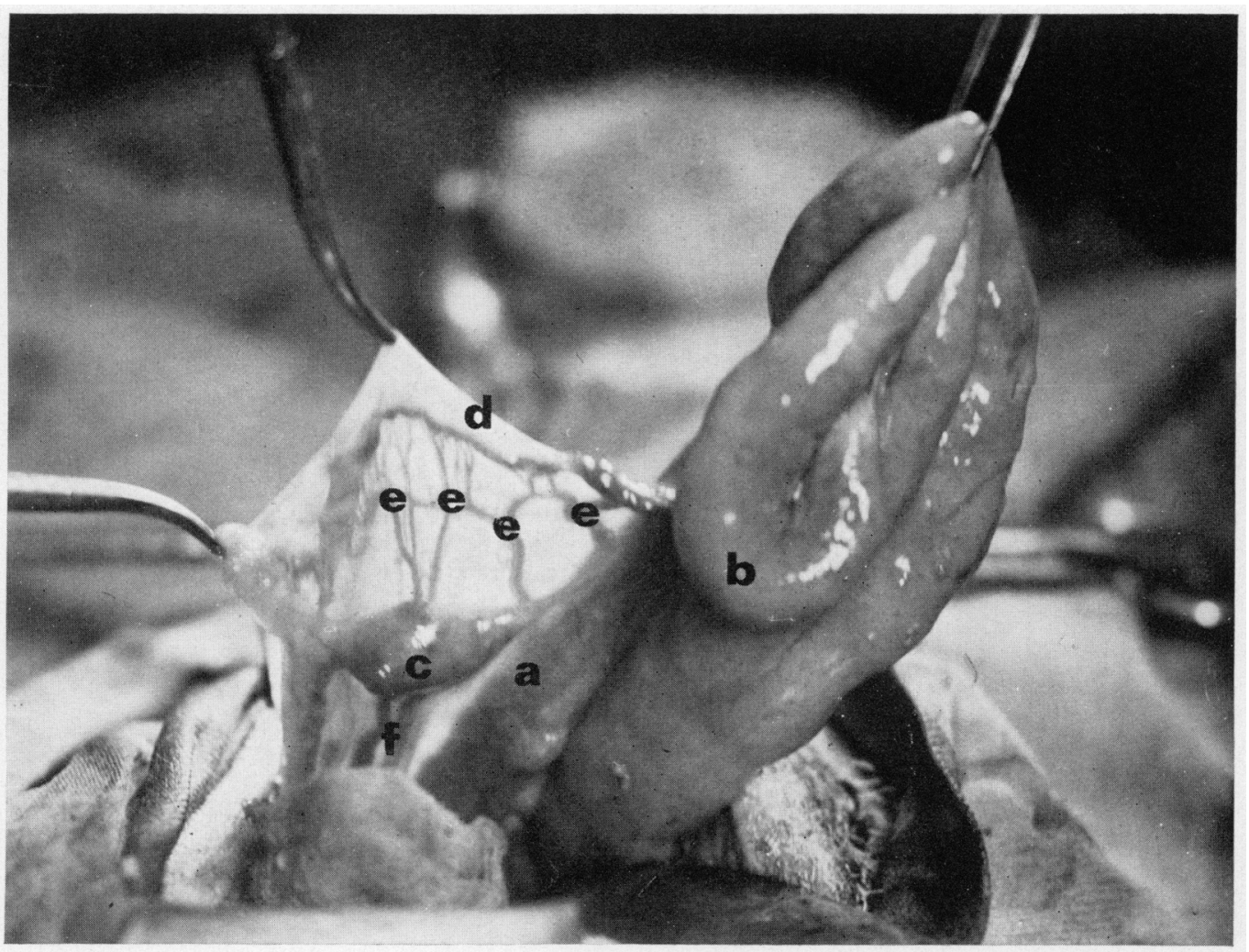

Photograph of the viscular supply to the uterus, lallopian tube and ovary in the ewe. a, Distended middle uterine vein; b, uterine homs; c, ovary; d, Fallopian tube; c, tubal veins; $f$, win ovarian veins. The nuddle uterine vein has becn ligated near its origin with the ovarian vein. 'The arcade of tubal veins can be seen clearly anastomosing with the uterine and ovarian veins. 
normal luteal regression. The presence of a tubal venous arcade of anastomotic vessels may explain the inconsistent results obtained when the middle uterine vein and artery were ligated (Kiracofe et al., 1966).

The present findings are therefore consistent with the hypothesis that a luteolytic substance (prostaglandin $F_{2 \alpha}$ ) is produced by the uterus, released into the uterine vein at the time of luteal regression, and transferred locally to the ovarian artery from the utero-ovarian vein (McCracken et al., 1971). The rate of transfer of $\left[{ }^{3} \mathrm{H}\right]$ prostaglandin $\mathrm{F}_{2 a}$ from the utero-ovarian vein to the ovarian artery is probably less than $0.2 \%$ (D. T. Baird, J. R. Goding, R. B. Land and I. S. Fraser, unpublished observations). However, because the ovarian artery is much more closely applied to the ovarian vein(s) distal to the utero-ovarian junction, a higher rate of transfer might be expected in this part of the pedicle. Blood draining through an anastomotic tubal branch of the uterine vein directly into the ovarian vein near the ovary would therefore be expected to have a greater effect than that draining directly into the middle uterine vein.

\section{ACKNOWLEDGMENTS}

The technical assistance of Miss Marjorie Fordyce, Mr A. G. Wheeler, $\mathrm{Mr}$ R. D. Preece, Mr A. Macgregor, Mr G. Davidson and Mr R. A. Collett and the gift of sponges from G. D. Searle Ltd is gratefully acknowledged. This work was supported in part by a grant from the Medical Research Council.

\section{REFERENCES}

Anderson, L. L., Bland, K. P. \& Melampy, R. M. (1969) Comparative aspects of uterine-luteal relationships. Recent Prog. Horm. Res. 25, 57.

Bland, K. P. \& Donovan, B. T. (1969) Observations on the time of action and the pathway of the uterine luteolytic effect of the guinea-pig. F. Endocr. 43, 259.

Butcher, R. L., BARLey, D. A. \& InskeEp, E. K. (1969) Local relationships between the ovary and uterus of rats and guinea pigs. Endocrinology, 84, 476.

Gollett, R. A., LAND, R. B. \& BAIRD, D. T. (1973) The pattern of progesterone secretion by the autotransplanted ovary of the ewe in response to ovine luteinizing hormone. F. Endocr. 56, 403.

Fischer, T. V. (1971) Local pathway controlling luteal function in the guinea pig. Biol. Reprod. 4, 126.

Goding, J. R., Harrison, F. A., Heap, R. B. \& Linzele, J. L. (1967) Ovarian activity in the ewe after autotransplantation of the ovary and uterus to the neck. F. Physiol., Lond. 191, 129.

Goding, J. R., McGracken, J. A. \& BAIRd, D. T. (1967) The study of ovarian function in the ewe by means of a vascular autotransplantation technique. J. Endocr. 39, 37.

INSKEeP, E. K. \& BuTCheR, R. L. (1966) The local component of utero-ovarian relationships in the ewe. F. Anim. Sci. 25, 1164.

Kiracofe, G. H., Menzies, G. S., Gier, H. T. \& Spies, H. G. (1966) Effect of uterine extracts and uterine or ovarian blood vessel ligation on ovarian function of ewes. F. Anim. Sci. 25, 1159.

McCracken, J. A., Baird, D. T. \& Goding, J. R. (1971) Factors affecting the secretion of steroids from the transplanted ovary in the sheep. Recent Prog. Horm. Res. 27, 537.

Moor, R. M. (1968) Effect of embryo on corpus luteum function. 7. Anim. Sci. 27, Suppl. 1, 97.

Moor, R. M. \& Rowson, L. E. A. (1966) Local uterine mechanisms affecting luteal function in the sheep. 7. Reprod. Fert. 11, 307.

OXENREIDER, S. L. \& DAY, B. N. (1967) Regression of corpora lutea in unilaterally pregnant guineapigs. F. Endocr. 38, 279.

Short, R. V. (1967) Reproduction. A. Rev. Physiol. 29, 373.

Wiltbank, J. N. \& Gasida, L. E. (1956) Alteration of ovarian activity by hysterectomy. F. Anim. Sci. $15,134$. 